\title{
AVALIAÇÃO DAS COMPETÊNCIAS DOS RECURSOS HUMANOS PARA A CONSOLIDAÇÃO DO SISTEMA ÚNICO DE SAÚDE NO BRASIL ${ }^{1}$ EVALUATION OF HUMAN RESOURCES COMPETENCES FOR THE CONSOLIDATION OF THE NATIONAL HEALTH CARE SYSTEM IN BRAZIL EVALUACIÓN DE LAS COMPETENCIAS DE LOS RECURSOS HUMANOS PARA LA CONSOLIDACIÓN DEL SISTEMA ÚNICO DE SALUD EN BRASIL
}

\author{
Rosita Saupe ${ }^{2}$, Agueda Lenita Pereira Wendhausen³, Gladys Amélia Vélez. Benito ${ }^{4}$ Luiz. Roberto Agea Cutolo ${ }^{5}$
}

\begin{abstract}
${ }^{1}$ Artigo resultado de pesquisa, conforme projeto submetido ao Edital No003/2003 daFundação de Ciênciae Tecnologia (FUNCITEC), atual Fundação de Apoio à Pesquisa Científica e Tecnológica do Estado de Santa Catarina (FAPESC), aprovado e financiado pela FUNCITEC, Ministério da Saúde (MS), Organização das Nações Unidas para a Educação, a Ciência e a Cultura (UNESCO). Vinculada ao Programa de Mestrado Profissionalizante em Saúde e Gestão do Trabalho; ao grupo de pesquisa em Educação na Saúde e Gestão do Trabalho; à linha de pesquisa Formação de Recursos Humanos na Saúde, da Universidade do Vale do Itajá (UNIVALI). Santa Catarina, Brasil.

${ }^{2}$ Enfermeira. Doutora em Enfermagem. Docente do Programa de Mestrado Profissionalizante em Saúde e Gestão do Trabalho da UNIVALI. Coordenadora do projeto. Santa Catarina, Brasil.

${ }^{3}$ Enfermeira. Doutora em Filosofia da Enfermagem. Coordenadora do Programa de Mestrado Profissionalizante em Saúde e Gestão do Trabalho da UNIVALI. Pesquisadora do projeto. Santa Catarina, Brasil.

${ }^{4}$ Enfermeira. Doutora em Engenharia de Produção. Docente do Programa de Mestrado Profissionalizante em Saúde e Gestão do Trabalho da UNIVALI. Pesquisadora do projeto. Santa Catarina, Brasil.

${ }^{5}$ Médico. Doutor em Educação. Docente do Programa de Mestrado Profissionalizante em Saúde e Gestão do Trabalho da UNIVALI. Pesquisador do projeto. Santa Catarina, Brasil.
\end{abstract}

PALAVRAS-CHAVE: Sistema Único de Saúde. Saúde da família. Educação baseada em competências. Recursos humanos em saúde. Avaliação.

KEYWORDS: Unique Health System. Family health. Competence-based education. Human manpower. Evaluation.

PALABRAS CLAVE: Sistema Único de Salud. Salud de la familia. Educación basada en competencias. Recursos humanos en salud. Evaluación.
RESUMO: Com o objetivo de avaliar as competências para educação e promoção da saúde, interdisciplinaridade e gerenciamento, usando modelo originário da University of North Carolina, foram entrevistados 21 peritos na temática. Todos os sujeitos eram profissionais da saúde atuando no território da $17^{a}$ Regional de Saúde de Santa Catarina, Brasil. Neste artigo apresentamos os resultados da construção do diagrama de árvore, do método do júri, da verificação da concordância entre os juizes e, também dos depoimentos. Os dados quantitativos foram analisados conforme estatística descritiva e os depoimentos usando análise de conteúdo. Os dados evidenciaram que as competências e suas dimensões foram positivamente avaliadas pelos peritos. $\mathrm{O}$ conjunto das respostas que receberam valor 4 e 5 alcançou 86,5\%. Estes dados e os depoimentos confirmam a procedência da proposta, o que nos autoriza a considerá-la um instrumento válido para ser incorporado nos programas educativos na área da saúde.

ABSTRACT: With the objective of evaluating the competences for health education and promotion, interdisciplinarity and management by using the original model from the University of North Carolina, 21 experts in the subject were interviewed. All of the subjects were health professionals performing in the $17^{\text {th }}$ Regional Health Area of Santa Catarina, Brazil. In this article, we present the results of the construction of the tree diagram, the jury method, verifying agreement among the judges, and of the depositions. The quantitative data were analyzed according to descriptive statistics and the depositions by using content analysis. The data evidenced that the competences and their dimensions were positively evaluated by the experts. The set of answers that received grades 4 and 5 reached $86,5 \%$. These data and the depositions have confirmed the source of the proposal what authorizes us to consider it an instrument valid to be incorporated in the educational programs in the health area.

RESUMEN: Con el objetivo de evaluar las competencias para la educación y promoción de la salud, la interdisciplinaridad y la administración, usando un modelo originario de la University of North Carolina, fueron entrevistados 21 peritos en el tema. Todos los sujetos eran profesionales del área dela salud, actuando en el territorio de la $17^{a}$ Regional de Salud de Santa Catarina, Brasil. En este artículo presentamos los resultados de la construcción del diagrama de árbol, de lo método del jurado, y de la verificación de la concordancia entre los jueces, así como también los resultados de los testimonios. Los datos cuantitativos fueron analizados según la estadística descriptiva y para los testimonios se usó el análisis de contenido. Los datos obtenidos demuestran que las competencias y sus dimensiones fueron positivamente evaluadas por los peritos. El conjunto de las respuestas que recibieron valor 4 y 5 alcanzó 86,5\%. Estos datos y los testimonios confirman la procedencia de la propuesta, lo que nos autoriza a considerarla un instrumento válido para ser incorporado en los programas educativos en el área de la salud.
Rosita Saupe

Endereço: R. Mediterrâneo, 172, Ap. 401

88.037-610 - Córrego Grande, Florianópolis, SC, Brasil.

E-mail:saupe@univali.br
Artigo original: Pesquisa Recebido em: 10 de abril de 2007 Aprovação final: 02 de outubro de 2007 


\section{INTRODUÇÃO}

O modelo biologicista hegemônico que tem conduzido a formação dos profissionais da saúde apresenta características marcadas por currículos organizados em disciplinas e grades curriculares que enfatizam o conhecimento das doenças e o tratamento dos doentes. Como conseqüência, o lócus privilegiado para o treinamento dos aprendizes é o hospital; o conceito de saúde dominante é representado pela ausência de doenças; e o domínio da alta complexidade tecnológica éa principal meta dos cursos e das instituições de saúde. Este modelo, e os espaços onde se desenvolve, exerce uma profunda atração, tanto sobre os ingressantes nas carreiras da saúde, quanto na maioria dos profissionais. Representa o grande desafio do conhecimento na área e a crença de que, quem domina este nível de complexidade torna-se capaz de atuar nos demais níveis "inferiores". No limite é a conquista do poder sobre a vida e a morte. Mas, o movimento de transformação deste modelo vem se fortalecendo nas últimas décadas, alavancado por políticas públicas aderidas às necessidades da população, como a Reforma Sanitária, implantada como Sistema Único de Saúde (SUS), bem como sua estratégia voltada para a Saúde da Família.

Na mesma perspectiva, a concretização da Lei de Diretrizes e Bases da Educação Nacional (LDB), através do estabelecimento das Diretrizes Curriculares (DC), encaminha para a formação de profissionais mais preparados para as novas exigências da sociedade. A articulação entre os programas do Ministério da Saúde e os Projetos Pedagógicos dos Cursos está em processo. Entre as possíveis sínteses que evidenciem a essência destas articulações, consideramos que o deslocamento da centralidade da formação para a promoção da saúde, a incorporação do conceito de saúde como qualidade de vida, o processo de trabalho pautado pela interdisciplinaridade, o desenvolvimento de competências, habilidadese atitudes para a ação social transformadora, fomentando a organização e a participação das pessoas, das famílias e das comunidades, bem como a capacitação para a educação em saúde e o gerenciamento, são aspectos fundamentais.

Todavia, muitos entraves precisam ser enfrentados: o temor pela perda de poder de algumas categorias; um entendimento equivocado de que as mudanças produzirão profissionais despreparados para a recuperação e reabilitação; o receio de esvaziamento dos currículos e dos cursos. Mas, a maior dificuldade, em nossa percepção, está no despreparo dos atuais educadores e trabalhadores da área da saúde para fomentarem e estimularem estas mudanças.
A era da incerteza que estamos vivendo, com acúmulodeexigênciasquantoàprodutividade, acompanhada peloenxugamentodonúmerode trabalhadoresnasvárias áreas, gera insegurança permanente, pois cada novo dia não é sentido como tempo para a criação, mas sim como um conjunto de obstáculos a serem vencidos e inimigos a serem abatidos, para garantir a sobrevivência. Neste contexto não é raro que discursos sobre as novas formas para enfrentamento desta realidade a ser superada, sejam recebidos com ironia e descrença. E aí se destaca a necessidade de produção de conhecimento que subsidie todos os atoresenvolvidos nesteprocesso. Foinestaperspectiva que este estudo foi proposto e desenvolvido.

A Reforma Sanitária vem buscando sua consolidação por meio da implantação de políticas públicas, articulando os esforços da área da saúde aos da educação, pois todos os programas que visam à transformação do modelo assistencial passam, necessariamente, por mudanças, tanto no perfil dos profissionais quanto na consciência coletiva das comunidades. Nesta perspectiva, a capacitação dos recursos humanos vinculados ao sistema de saúde, (futuros e atuais profissionais, gerentes, líderes comunitários e conselheiros de saúde), tanto no sistema formal de ensino, quanto nos processos de educação permanente, precisa resultar da integração de esforços e serem acompanhados por avaliação que indique a necessidade de ajustes, reforços e redirecionamentos, para que desvios possam ser corrigidos antes que produzam efeitos indesejados.

Assim, as políticas públicas em saúde, representadas pelo SUS e a Estratégia de Saúde da Família (ESF) e as políticas públicas na área da educação, a saber, a LDB e sua implementação no ensino superior, através das DC, fundamentam esta pesquisa, não somente como normalização legal, mas principalmente quanto aos desdobramentos decorrentes de sua operacionalização, mais especificamente no que se refere às competências dos recursos humanos em saúde para concretização destas políticas.

O presente estudo teve como objetivo avaliar as competências dos recursos humanos comprometidos com a consolidação do SUS, através da ESF. Competências que promovem a integração entre as políticas públicas em saúde e em educação e rompem com a histórica dicotomia entre estes setores. Competências entendidas como o conjunto de conhecimentos, habilidades e atitudes necessárias aos recursos humanos em saúde para consolidação do SUS/ESF. Competências que devem constar do projeto pedagógico dos cursos, das atribuições dos profissionais e dos programas de capacitação e de educação permanente. 
Na delimitação do estudo foram selecionadas as competências gerais, incluídas nas DC para os cursos na área da saúde, ${ }^{1}$ que independem da profissão e que contribuem para o fortalecimento do trabalho em equipe, a saber: educação e participação, interdisciplinaridade e gerenciamento.

\section{REFERENCIAL TEÓRICO}

Entre os modelos referidos na literatura, ${ }^{2-3}$ como possibilidades de sustentação teórica para o desenvolvimento de pesquisas, optamos por um conjunto de conceitos. A seleção dos mesmos incluiu: competência e seus desdobramentos em conhecimentos, habilidades e atitudes. Quanto à decisão de considerar uma competência como o resultado de um conjunto de conhecimentos, habilidades e atitudes, além do consenso entre os pesquisadores, encontramos também apoio em outros autores. ${ }^{4.6}$

Assim, para este estudo "competência é o resultado de um conjunto de capacidades referidas aos conhecimentos, às habilidades e às atitudes, que conferem ao profissional condições para desenvolver seu trabalho". 7:33 Os conhecimentos e saberes do domínio cognitivo são representados pelo "conjunto de conteúdos obtidos predominantemente por meio de exposição, leitura e re-elaboração crítica, que possibilitam ao profissional o domínio cognitivo de um saber e a capacidade de tomar decisões e resolver problemas em sua área de atuação" : $: 33$ As habilidades representam o saber fazer do domínio psicomotor e são indicadas pelo "conjunto de práticas adquiridas, sobretudo por demonstração, repetição e re-elaboração crítica, que fornecem ao profissional o domínio psicomotor, a perícia de um saber fazer e a capacidade de tomar decisões e resolver questões no seu campo de atuação" ${ }^{7: 33}$ As atitudes, que representam o saber ser e conviver do domínio afetivo compreendem o "conjunto de comportamentos adquiridos por intermédio de observação, introjeção e re-elaboração crítica que conferem ao profissional o domínio ético e afetivo de um saber ser e saber conviver, além da capacidade de tomar decisões e de solucionar problemas na sua área de atuação". 7:33

\section{METODOLOGIA}

A metodologiaselecionada paraconduzir acoleta e análise dos dados foi adaptada de um modelo que tem sua origem na University of North Carolina - EUA, proposta no início da década de setenta, introduzida no Brasil em meados da mesma década e utilizada na avaliação de alguns programas. ${ }^{9-10}$ Esta metodologia é composta por várias etapas. Neste estudo foram utilizadas as etapas a seguir.

Construção do Diagrama de Árvore - decomposição do tema em estudo em seus vários componentes, resultando num desenho que estabelece, de forma hierárquica, os vários desdobramentos ou variáveis a serem consideradas.

Aplicação do Método do Júri - no qual um grupo impar de especialistas é solicitado, por meio de entrevista individual, a atribuir pesos ou valores a cada variável componente do diagrama, conforme uma escala previamente apresentada ao mesmo. Para atribuir o peso, o juiz é orientado a considerar o valor da variável em comparação as demais, do mesmo nível de decomposição. O peso 1 é atribuído a(s) variável(eis) a(s) qual(is) associa-se um valor "muito baixo", em seu grupo e nível de desdobramento; o peso 2 é associado a um valor "baixo"; o peso 3 corresponde ao valor "mediano"; o peso 4 ao valor "alto"; e, finalmente, o peso 5 ao valor "muito alto". Para este estudo foram selecionados e convidados 21 profissionais da área da saúde. Foram incluídos de forma intencional, considerando-se os critérios de experiência na área do estudo e acesso dos pesquisadores aos mesmos, desde que aceitassem participar do estudo e disponibilizassem o tempo necessário para a realização da entrevista. Após a atribuição dos pesos aos vários componentes do diagrama de árvore, os juizes foram convidados a apresentarem um depoimento relacionado ao tema da pesquisa. As falas foram gravadas, transcritas e analisadas em seu conteudo. ${ }^{11}$

Verificação da Concordância entre os Juízes - esta concordância ocorre naturalmente quando todos os juízes atribuem o mesmo valor a mesma variável. No caso de não concordância, utiliza-se da mediana para estabelecer o valor do peso.

Esta pesquisa foi desenvolvida no território de maior influência da Universidade do Vale do Itajaí (UNIVALI) - local de trabalho dos pesquisadores a $17^{\text {a }}$ Regional de Saúde de Santa Catarina. Assim, os juizes consultados atuavam num dos 11 municípios que a compõem, a saber: Itajaí, Luiz Alves, Navegantes, Camboriú,Piçarras, Ilhota,Balneário Camboriú, Porto Belo, Itapema, Bombinhas e Penha.

Todos os sujeitos assinaram o Termo de Consentimento Livre e Esclarecido (TCLE). O projeto foi aprovado pelo Comitê de Ética da UNIVALI, sob N ${ }^{\circ}$ $381 / 2003$. 


\section{RESULTADOS}

\section{Primeira etapa: construção do diagrama de árvore}

Esta etapa foi realizada pelos pesquisadores, fundamentados na literatura ${ }^{4-6} \mathrm{e}$ em sua experiência profis- sional. O modelo processual para construção do Diagrama de Árvore iniciou com a seleção das competências a serem focalizadas no estudo, que foram: Educação e Participação; Interdisciplinaridade; e, Gerenciamento, em suas dimensões de conhecimentos, habilidades e atitudes, conforme apresenta a Figura 1.

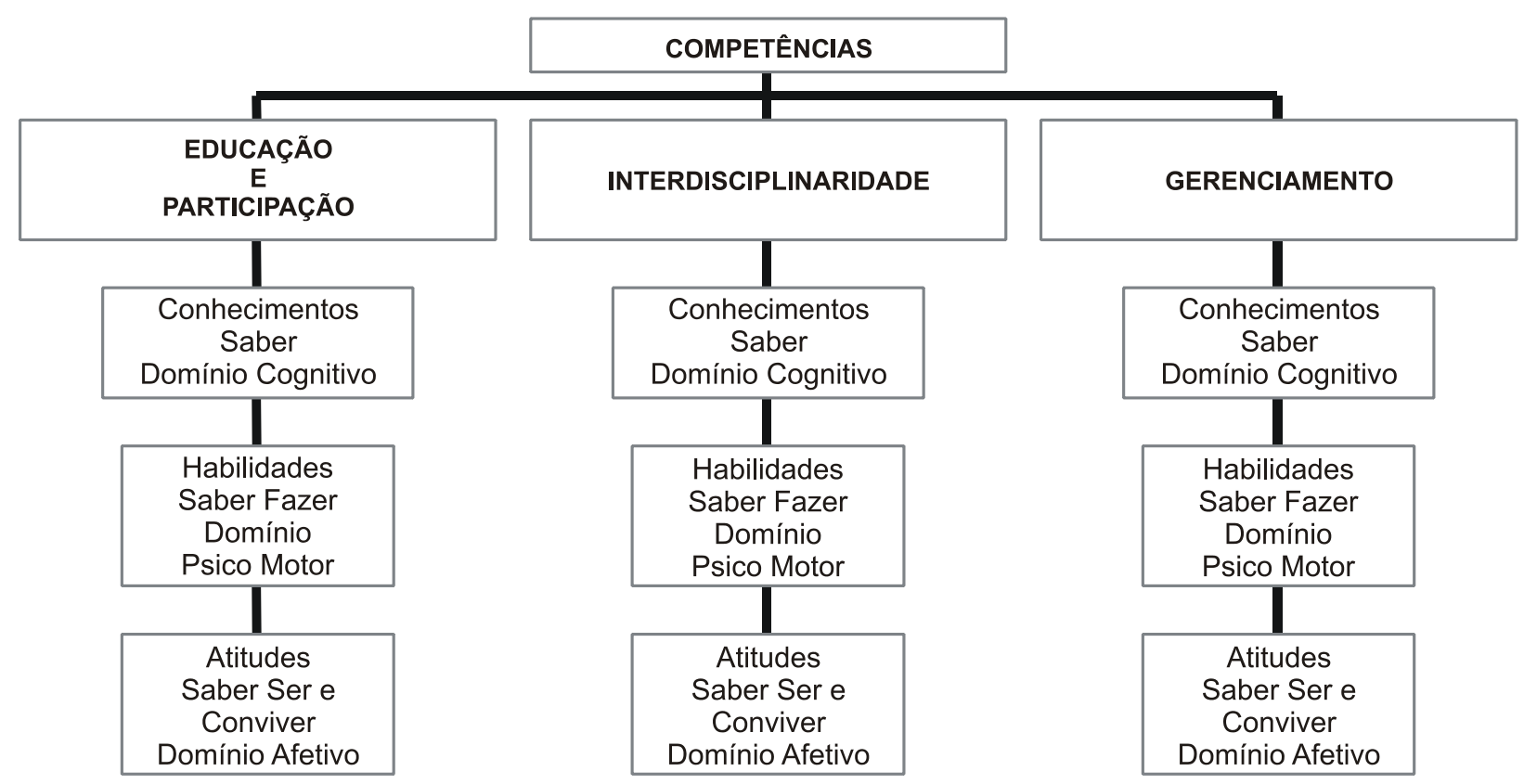

Figura 1 - Diagrama de Árvore representando as competências estudadas. Itajaí - SC, 2005.

A partir deste diagrama matricial foram construídos mais três, cada um representando uma das competências e seus componentes, desdobrados em conhecimentos, habilidades e atitudes. Na seqüência estão descritos os componentes incluídos.

A competência para educação e participação foi entendida como o resultado de: ${ }^{12}$

1) conhecimentos sobre educação (incluindo: as políticas e programas em educação na saúde; as teorias da educação; as teorias do ensino e da aprendizagem; metodologias e tecnologias de educação e participação; e as teorias da comunicação) efamília (teorias de família; princípios éticos nas ações de saúde e conflito moral; fundamentos de antropologia e cultura popular);

2) habilidades para o trabalho em grupo (motivar as pessoas; comunicar, ouvir e falar; compartilhar; pactuar); para a ação educativa (planejar, desenvolver e avaliar);

3) já quanto às atitudes, foram consideradas fundamentais a reflexão (reconhecer-se como educador e acreditar nas potencialidades das pessoas); a preocupação com a educação permanente; a valorização da participação (atitude de motivar para a participação com respeito aos valores culturais); e a ética, que inclui o respeito aos critérios democráticos, o saber conviver e a aceitação das diferenças.

O desdobramento da competência para a interdisciplinaridade considerou:

1) os conhecimentos sobre a teoria geral da interdisciplinaridade (histórico, conceitos de pluri, multi, trans e interdisciplinaridade); sobre as políticas doSUS para recursos humanos; e as diretrizes curriculares gerais dos cursos da área da saúde;

2) as habilidades necessárias a esta competência foram concentradas em: trabalho em equipe; comunicação e resolução de problemas coletivamente;

3) como atitudes fundamentais para desenvolver a interdisciplinaridade: a pluralidade de visão; a flexibilidade; a tolerância e a capacidade de ouvir e falar.

A terceira e última competência selecionada para ser avaliada neste estudo foi o gerenciamento. $\mathrm{Da}$ mesma forma foram delimitados os conhecimentos, as habilidades eas atitudes consideradas mais significativas pelos autores, com apoio da literatura: 
1) os conhecimentos focalizaram: o planejamento das ações (para o qual é necessário conhecer os fatores determinantes do processo saúde-doença e o perfil epidemiológico da população); a promoção e vigilância da saúde; o conhecimento sobre o trabalho de todos os componentes das equipes de saúde; a abordagem integral da família;

2) como habilidades para o gerenciamento, incluímos a capacidade de estabelecer prioridades; de saber traçar estratégias; de articular ações integradas com outros setores da sociedade e com a rede institucional; bem como de desenvolver treinamento de pessoal auxiliar, voluntários, estagiários. A abordagem integral da família de forma participativa e construtivista, a identificação das formas de relação da mesma com a comunidade e a sensibilidade para identificar violência no meio familiar, foram consideradas habilidades da maior relevância;

3) as atitudes descritas como: respeitar e acolher as necessidades de saúde das famílias e das equipes; respeitar e acolher as formas de cuidado das famílias e das equipes; valorizar a participação comunitária; saber compartilhar conhecimentos e informações; e respeitar e valorizar as características do núcleo familiar e da comunidade, completaram os requisitos para a competência no gerenciamento dos serviços de saúde.

Este detalhamento das competências em seus desdobramentos quanto aos conhecimentos, habilidades e atitudes, gerou 86 componentes que foram submetidos à apreciação de um grupo de juízes, conforme descrito a seguir.

\section{Segunda etapa: método do júri}

Foi selecionado um corpo de experts, considerados peritos na temática em estudo, aos quais foram submetidos os diagramas construídos. Todos os selecionados, quando convidados, aceitaram participar, assinando o TCLE. O grupo de juízes foi composto por 21 profissionais da saúde, sendo 7 enfermeiros, 6 odontólogos, 4 médicos, e um representante de cada uma das seguintes profissões: Farmácia, Fonoaudiologia, Fisioterapia e Psicologia. A consulta foi realizada por meio de entrevista previamente agendada, com tempo de duração médio de 23 minutos, sendo o mínimo de 10 e o máximo de 33 minutos.

A caracterização dos juízes mostra um grupo de 14 profissionais do sexo feminino e 7 do masculino; com idade média de 39 anos; todos com pós graduação, sendo 6 mestres e os demais especialistas freqüentando mestrado; com tempo médio de graduação em 16 anos, com variação entre 7 e 26 anos.

Estes juízes avaliaram um conjunto de componentes referentes aos conhecimentos, habilidades e atitudes, propostos pelos pesquisadores, como necessários ao desenvolvimento das competências para Educação e Participação em Saúde; Interdisciplinaridade; e Gerenciamento.

A avaliação dos juízes gerou 1806 ocorrências (21 juízes x 86 quesitos avaliados). Estas ficaram assim distribuídas entre as cinco possibilidades oferecidas pela escala Likert:

- peso 1: importância muito baixa atribuída ao componente: 1 ocorrência;

- peso 2: importância baixa atribuída ao componente: 27 ocorrências;

- peso 3: importância mediana atribuída ao componente: 216 ocorrências;

- peso 4: importância alta atribuída ao componente: 654 ocorrências;

- peso 5: importância muito alta atribuída ao componente: 908 ocorrências.

Estes dados evidenciam a positiva avaliação dos quesitos submetidos aos juízes. Verificamos que $86,5 \%$ das respostas ficaram concentradas no conjunto formado pelos pesos 4: importância alta e 5: importância muito alta. $\mathrm{O}$ total das demais opções (peso 1, 2 e 3), que chegou somente a 13,5\%, reforça esta afirmação.

\section{Terceira etapa: verificação da concordância entre os juízes}

Apresentamos a seguir o desempenho das competências para Educação e Participação, Interdisciplinaridade e Gerenciamento.

\section{Educação e participação}

$\mathrm{Na}$ Figura 2 apresentamos o desempenho da competência para Educação e Participação. Na seqüência 1 temos a distribuição conforme números absolutos e na seqüência 2, em percentuais, confirmando a curva ascendente apresentada pelos dados.

Cinco componentes da competência para Educação e Participação (Teorias da Educação; Teorias de Ensino Aprendizagem; Teorias da Comunicação; e, Teorias de Família, estes relativos aos Conhecimentos); e um componente das Habilidades (Saber Pactuar) receberam avaliações mais baixas. 
Em relação aos três primeiros componentes, muito provavelmente a tradicional dificuldade de aceitação da dimensão educativa no trabalho dos profissionais de saúde ou a crença de que basta o domínio de conhecimentos específicos para se fazer educação em saúde, pode ser uma explicação para este fato. Quanto aos demais componentes (Teorias da Comunicação, Teorias de Família e Saber Pactuar), nos parecem tão diretamente relacionados às ações próprias do cotidiano do trabalho no SUS/PSF, que esperávamos uma avaliação mais positiva.

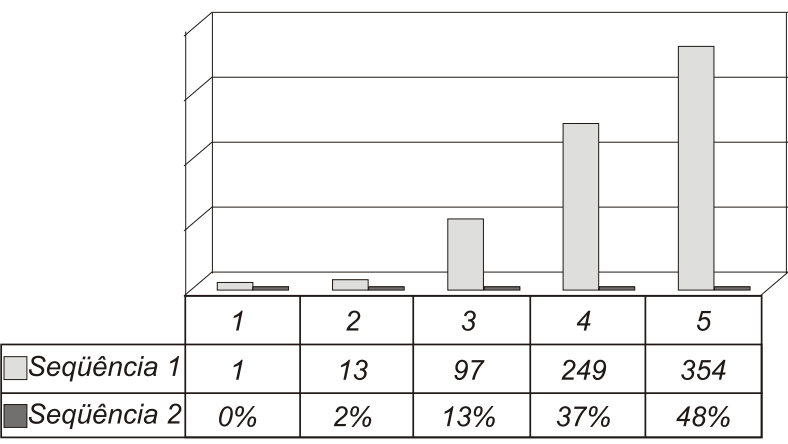

Figura 2 - Distribuição dos pesos atribuídos à competência para Educação e Participação. Itajaí - SC, 2005.

Em relação às Teorias de Família, em especial, faz-se necessária alguma reflexão. Revendo os documentos oficiais sobre o PSF, ${ }^{13}$ constatamos que há poucas menções à abordagem da família como unidade para a prestação da assistência. Em estudo sobre as noções teóricas sobre família e saúde da família de algumas publicações do Ministério da Saúde (56 ao todo), as autoras concluem que embora o Programa esteja centrado na saúde da família, seu conceito não surge claramente formulado. ${ }^{14} \mathrm{~A}$ família é considerada cuidadora de seus membros e um espaço onde se constrói saúde, mas a idéia ainda é sobre a saúde dos membros da família e não dela enquanto unidade. Pensamos que a relativa importância dada pelos profissionais neste item tenha relação com o desconhecimento da existência de teorias para cuidar de famílias. Seria importante, pois que se começasse a investir nesta temática, tanto na formação em nível de graduação como no latu e stricto sensu.

Um aspecto que consideramos muito promissor, refere-se ao componente mais bem pontuado que diz respeito à Atitude de "Acreditar nas potencialidades das pessoas", confirmando o acerto de nossa decisão de incluir esta dimensão das competências, mesmo que não esteja sendo considerada em documentos importantes como as Diretrizes Curriculares, que focalizam somente conhecimentos e habilidades.

\section{Interdisciplinaridade}

A análise da Figura 3, que trata da competência para Interdisciplinaridade, segue a mesma orientação da Figura 2, quanto a compreensão das seqüências 1 e 2 . Os percentuais obtidos por todos os valores estão muito próximos aos alcançados pela competência para Educação e Participação, mostrando homogeneidade nas avaliações dos peritos.

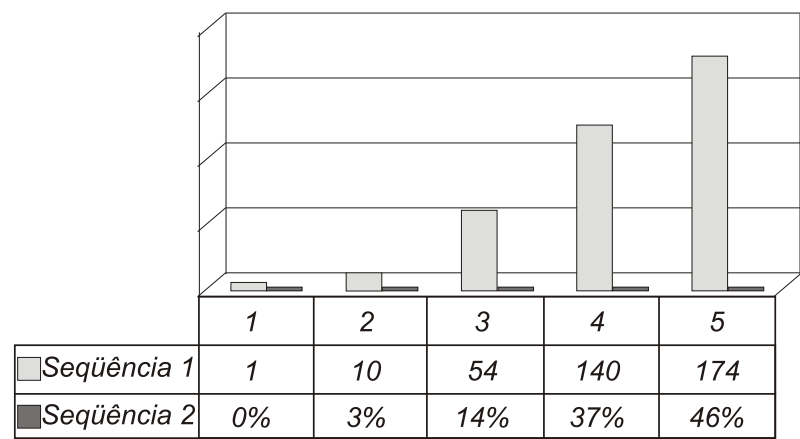

Figura 3 - Distribuição dos pesos atribuídos à competência para a Interdisciplinaridade. Itajaí - SC, 2005.

Dos dezoito componentes selecionados para avaliar a competência para a Interdisciplinaridade, os dois que receberam avaliação mais baixa estavam relacionados aos Conhecimentos. São eles: Teoria Geral e Histórico da Interdisciplinaridade. Não compartilhamos com o pragmatismo evidenciado pelos juízes, pois apesar de concordarmos que Interdisciplinaridade é um conceito que só se concretiza na realidade das ações, como tantos outros, não dispensa ou anula a necessidade teórica para sua compreensão. Sem eliminar a subjetividade presente e necessária aos atos humanos, precisamos superar práticas pautadas somente pela intuição. Por outro lado, a concentração de avaliações positivas atribuídas as Atitudes, está plenamente afinada com a perspectiva deste estudo e com o momento histórico de sua realização. ${ }^{12}$

\section{Gerenciamento}

A Figura 4 trata da competência para o Gerenciamento e mostra as mesmas tendências dos anteriores, todavia com percentual mais elevado no valor 5 . 


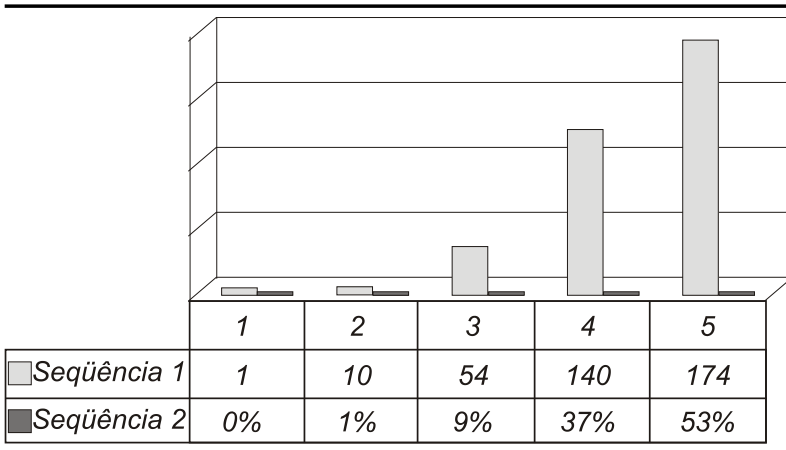

Figura 4 - Distribuição dos pesos atribuídos à competência para o gerenciamento. Itajaí - SC, 2005.

Como os juízes que selecionamos são coordenadores de cursos ou profissionais com vínculos consolidados na Atenção Primária e comprometidos com o SUS/ESF, sua avaliação emerge de seu cotidiano e preocupações em tornar o Gerenciamento uma prática que, assim como a educação em saúde, precisa ser reavaliada, revitalizada e re-elaborada criticamente. Afirmamos que é urgente ultrapassar a fase simplória da ingenuidade que acredita que para gerenciar serviços de saúde basta ser um bom profissional da área. A necessidade de instrumentalização para o gerenciamento começa a ser percebida em sua importância para a concretização dos princípios norteadores do SUS/PSF em todas as dimensões.

Por outro lado, para que se instale um novo modelo de saúde, a ESF tem expressado muito mais sua face gerencial, do que a assistencial. Disto decorre que no cotidiano se ressalta mais o que deve se modificar em termos de gestão (a compreensão e uso de dados epidemiológicos, o percurso do usuário no sistema, a adscrição da clientela, etc) do que o como deve ser a prestação de assistência na busca do paradigma sanitário. ${ }^{15}$

Trazendo as possibilidades metodológicas para implantação do distrito sanitário (modelo adotado pelo SUS) ressalta-se seu caráter de processo social de mudança nas práticas de saúde, em que se faz necessária à integração de vários níveis: o jurídico, o institucional e o operativo. Chama atenção, no entanto, de que a prática brasileira tem sido mudar a forma e estrutura dos serviços, sem tocar no mais importante que seria a mudança do paradigma assistencial, o que passa muito mais pela nova relação a ser estabelecida entre os diversos atores que negociam um projeto de cuidado à saúde. ${ }^{15}$

$\mathrm{Na}$ avaliação desta competência, mereceu destaque pelos juízes a Habilidade para 'Estabelecer Prioridades', competência da maior relevância, principalmente em sistemas de saúde que tem que conviver com a carência crônica de recursos. Por outro lado, atribuir valor menor a Habilidade de 'Abordagem Integral da Família', bem como a um dos itens de sua decomposição, 'Identificar violência no meio familiar', parece não considerar a extrema atualidade destes temas e sua importância nas ações de saúde.

\section{Depoimentos}

Ao concluir a atribuição dos pesos, os juízes foram estimulados a emitirem depoimentos relacionados ao tema. Somente um entrevistado não quis se pronunciar. As falas foram gravadas, transcritas e analisadas em seu conteúdo. ${ }^{11}$

Os depoimentos mais presentes referiram a importância da pesquisa; a avaliação do instrumento, em sua forma e conteúdo; a dificuldade em estabelecer comparação entre os vários componentes de cada competência, já que todos pareciam da maior relevância e merecedores do valor mais alto.

Quanto à importância da pesquisa, o foco mais presente nas falas dos entrevistados tem a ver com a relação que estabeleceram entre o tema estudado e a consolidação do SUS. Entendem que esta é uma necessidade urgente, mas que é [...] algo novo, muito novo... na nossa formação [...] (Juiz 2), e que, [...] na verdade nós não sabemos exatamente como fazer [...] (Juiz.3). Transcrevemos a seguir um depoimento, que expressa a síntese das falas relacionadas à importância do estudo: Acredito que esse tipo de trabalho é que vai fazer com que o SUS se consolide, com que o PSF tenha a estratégia dele aplicada na prática (Juiz 10).

A avaliação do instrumento recebeu tanto louvores, quanto críticas. Alguns juízes o consideraram muito longo, ou de difícil compreensão. Quanto ao tamanho, temos de concordar, já que no projeto pretendíamos realizar a coleta de dados com populações e amostras diferentes, usando para isto instrumentos relacionados a cada competência especificamente. Todavia, ao desenvolvermos os estudos para definir as competências, suas dimensões e componentes, chegamos à conclusão de que a pesquisa ficaria mais rica se todos os sujeitos tivessem a oportunidade de opinar sobre todas as competências. Os aspectos positivos, relacionados ao instrumento aplicado aos juízes, foram atribuídos em função de sua originalidade, na forma de diagrama de árvore e de estar muito completo, incluindo tudo que consideravam importante para o desenvolvimento das competências estudadas. Esta posição foi majoritária.

A dificuldade em estabelecer comparação entre os vários componentes de uma dimensão pode 
ser ilustrada pela fala do juiz 16: achei difficil avaliar por pesos... todos são importantes... não sei como dizer isto é mais importante que aquilo [...].

As omissões de abordagem nas falas dos juízes também são importantes. Nossa expectativa era de que verbalizassem também seu preparo pessoal para o desenvolvimento das competências analisadas, $\mathrm{o}$ que não ocorreu. Esperávamos também que abordassem a questão da educação permanente para o SUS/ESF. Para não dizer que esta omissão foi absoluta, transcrevemos o depoimento de um juiz que, antevendo a próxima etapa deste estudo, colocou: [...] quem vai poder colaborar muito... são os profissionais que estão atuando na ponta.. as experiências deles... a atitude deles... vão acrescentar muito neste trabalho (Juiz 8).

\section{CONCLUSÕES}

O objetivo deste estudo, foi avaliar um conjunto de competências consideradas nucleares para a capacitação de recursos humanos em saúde, na perspectiva de consolidação do SUS/ESF. Entendemos que o mesmo foi atingido. Foram consultados 21 juízes, incluindo representação das profissões da área da saúde que tradicionalmente estão inseridas na saúde coletiva e conseqüentemente nas novas políticas públicas tais como a ESF. Os resultados evidenciaram a procedência da proposta, o que nos autoriza a considerá-la um instrumento válido para a incorporação nos Projetos Pedagógicos dos Cursos e nos Programas de Educação Permanente na área da saúde, na perspectiva de consolidação da Reforma Sanitária.

Como qualquer iniciativa humana, este estudo apresenta também as suas limitações. O território abrangido pela pesquisa, a $17^{2}$ Regional de Saúde de Santa Catarina, inclui somente 11 municípios, o que delimita a compreensão dos dados e sua aplicação sem estudo semelhante em outros locais. A complexidade da metodologia gerou muitas informações, tornando necessária sua divulgação parceladamente, o que pode dificultar o entendimento. A necessidade de delimitar o número de competências a serem estudadas resulta numa visão parcial sobre as competências necessárias aos recursos humanos para consolidação do SUS/PSF. Outros estudos se fazem necessários, abordando as mesmas competências em outras realidades e outros espaços territoriais.

\section{REFERÊNCIAS}

1 Almeida M. Diretrizes curriculares nacionais para os cursos universitários da área da saúde. Londrina (PR): Rede UNIDA; 2003.
2 Trentini M. Relação entre teoria, pesquisa e prática. Rev. Esc. Enferm. USP 1987 Ago; 21 (2): 135-43.

3 Minayo MCS. O desafio do conhecimento: pesquisa qualitativa em saúde. São Paulo (SP)/Rio de Janeiro (RJ): Hucitec/Abrasco; 1992.

4 Perrenoud P. Construir as competências desde a escola. Porto Alegre: (RS): ARTMED; 1999.

5 Delors J. Educação: um tesouro a descobrir. São Paulo (SP)/Brasília (DF): Cortez/MEC/UNESCO; 1998.

6 Witt RR, Almeida MCP. O modelo de competências e as mudanças no mundo do trabalho: implicações para a enfermagem na atenção básica no referencial das funções essenciais de saúde pública. Texto Contexto Enferm. 2003 Out-Dez; 12 (4): 559-68.

7 Saupe R, Benito GAV, Wendhausen ALP, Cutolo, LRA. Conceito de competência: validação por profissionais de saúde. Saúde Rev. 2006 Jan/Abr; 8 (18): 31-7.

8 Spínola M, Pereira E. Avaliação de programas: uma metodologia. Projeção. 1976 sem mês; 7 (1): 26-32.

9 Spínola M, Pereira E. Avaliação do programa imposto de renda: 77. Projeção 1977; 19 (Supl.): 1-11.

10 Saupe R. Avaliação do curso de enfermagem da UFSC conforme opinião de egressos e empregadores. Rev Ciên. Saúde 1983 Jun; 2 (3): 55-70.

11 Triviños AN. Introdução à pesquisa em ciências sociais: a pesquisa qualitativa em educação. São Paulo (SP): Atlas; 1987.

12 Saupe R, Cutolo LRA, Wendhausen, ALP, Benito GAV. Competência dos profissionais da saúde para o trabalho interdisciplinar. Interface-Comunic Saúde Educ. 2005 Set/Dez; 9 (18): 521-36.

13 Costa Neto MM, organizador. Cadernos de atenção básica. A implantação da unidade de saúde da família. Brasília (DF): MS/Departamento de Atenção Básica; 1999.

14 Elsen I, Altoff CR, Manfrini GC. Saúde da família: desafios teóricos. Saúde Família e Desenvolv. 2001 Jul/Ago; 3 (2):89-97.

15 Mendes EV, organizador. Distrito sanitário o processo social de mudança das práticas sanitárias do Sistema Único de Saúde. São Paulo (SP)/Rio de Janeiro (RJ): Hucitec/Abrasco; 1999.

\section{AGRADECIMENTOS}

Às pessoas que colaboraram: sujeitos da pesquisa; bolsistas; apoio logístico; colegas e alunos do Curso de Mestrado Profissionalizante em Saúde e Gestão do Trabalho. Ás instituições: UNESCO, FAPESC; Ministério da Saúde;

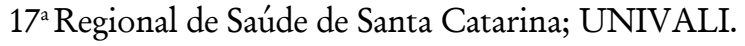

